\title{
Magnetic properties of hemoilmenite single crystals in Haruna dacite pumice revealed by the Bitter technique, with special reference to self-reversal of thermoremanent magnetization
}

\author{
Mituko Ozima and Minoru Funaki \\ National Institute of Polar Research, Kaga, Itabashi, Tokyo 173-8515, Japan \\ (Received March 24, 2000; Revised November 27, 2000; Accepted November 28, 2000)
}

\begin{abstract}
In order to reconsider the mechanism of the self-reversal of TRM (SRTRM) of hemoilmenite in dacite pumice, magnetic properties of newly collected Haruna dacite pumice near the historical sampling site (more than 50 years ago) were investigated again. All Haruna dacite pumice samples collected showed SRTRM or at least partial SRTRM. This time, the methods of microprobe analysis and the Bitter technique which were not available 50 years ago, were added to examine hemoilmenite crystals. Contrary to the result which was first reported by Hoffmann and Fehr on the basis of the micromagnetic observation of hemoilmenite crystals in Pinatubo dacite pumice, our hemoilmenite crystals are considerably more homogeneous in $\mathrm{TiO}_{2}$-content in a single crystal than those of Hoffmann and Fehr. Also, we could not find any "shell structure" with two phases having different magnetism and compositions in a single crystal of hemoilmenite in Haruna dacite pumice. We came to the conclusion that the intergrown shell-structure itself in Hoffmann and Fehr's model may not be essential but only the coexistence of the intergrown two phases in a single crystal of hemoilmenite must be essential for the acquisition of SRTRM of hemoilmenite. Both models, one by Ishikawa and Syono and the other by Hoffmann and Fehr are basically similar to each other, regardless of the structure involved.
\end{abstract}

\section{Introduction}

Since the self-reversal of TRM (or self-reversed TRM: SRTRM) in natural rocks had been first discovered in dacite pumice of Haruna volcano (Nagata et al., 1951) (geologically, dacite pumice fall and/or flow of Futatsu-dake in Haruna volcano erupted in the sixth century), a number of studies on the magnetic properties of ilmenite-hematite series with special reference to this phenomenon have been carried out (e.g., Uyeda, 1958; Ishikawa, 1962). Recently, similar cases of SRTRM in some other dacite/andesite pumices have been reported (Kennedy, 1981; Heller et al., 1986; Lawson et al., 1987; Ozima et al., 1992). For thirty years, after SRTRM was first discovered in Haruna dacite pumice, SRTRM of this type was believed to be uncommon in nature. However, nowadays we know that many other dacite pumices in Japan show SRTRM (Sawada et al., 1999; Oshima, private communication, 1999). Petrologically, Oshima (e.g., 1975) showed that dacite pumice contains hemoilmenite of some compositions $\left(\mathrm{TiO}_{2} \sim 30 \mathrm{wt} \%\right)$ and it should show SRTRM. Therefore, SRTRM in nature would be more common than we had thought for many years. We have rarely used pumices for paleomagnetic study and this situation may have caused our belief that SRTRM is very rare in nature. Recently, many geologists have used remanent magnetization of pumice in order to estimate the settling temperature of pumice in pyroclastics, and we became very interested in the magnetic

Copy right $(\mathcal{C}$ The Society of Geomagnetism and Earth, Planetary and Space Sciences (SGEPSS); The Seismological Society of Japan; The Volcanological Society of Japan; The Geodetic Society of Japan; The Japanese Society for Planetary Sciences. properties of pumice.

The possible physical mechanisms of SRTRM of this type have been proposed by several authors (Uyeda, 1958; Ishikawa and Syono, 1962, 1963; Nord and Lawson, 1989; Hoffman, 1992; Haag et al., 1993; Hoffmann and Fehr, 1996). Among those, the spin rotation model of Hoffman (1992) is slightly different from the other five. The following three points are common to all five models in our concept, i.e., (1) the carrier of the SRTRM is a ferrimagnetic hemoilmenite phase (ordered phase) of $X_{i l m}$ around 0.5 ( $X_{i l m}$ : ilmenite molecular fraction); (2) the SRTRM is a result of a negative exchange interaction between two hemoilmenite phases; (3) the order-disorder transformation of hemoilmenite is deeply related to the acquisition of the SRTRM. What is the other hemoilmenite phase which turns the TRM of the ordered ferrimagnetic hemoilmenite phase into the reversed direction? On this point, Uyeda (1958) concluded that the SRTRM is a result of an exchange interaction between the disordered and ordered phases of a hemoilmenite (the chemical composition is just the same for both phases) during the cooling process in the geomagnetic field. The compositional range of hemoilmenite is restricted to show SRTRM as $0.45 \leq X_{\text {ilm }} \leq 0.6$. However, Ishikawa (1962) pointed out that Uyeda's conclusion on the interaction was not true. According to Ishikawa's phase-diagram of hematite-ilmenite series, when the chemical composition is the same for both phases, the Curie point of the ordered phase is higher than that of the disordered phase. On the basis of this experimental result, Ishikawa and Syono (1962) introduced the third phase (the "X-phase") which has a Curie point higher than that of the ordered phase. This 
phase is supposed to be temporally produced at the margin of the ordered phase during the disordered-to-ordered phase transition on cooling. The ordered phase is magnetized antiparallel to the external field due to the negative exchange interaction with the normal magnetization of the "X-phase" through the anti-phase boundary. Finally, the "X-phase" disappears as the transition proceeds and, at the same time, the normal magnetization vanishes, leaving only the reversed magnetization of the ordered phase. Therefore, SRTRM is an intrinsic property of hemoilmenite in this compositional range. Ishikawa and Syono's model was so clever and firmly based on the physical data that it has been a unique model for many years, until Nord and Lawson (1989) proposed a model of the twin-(cation-ordered)domain boundary and some other models were successively proposed.

Hoffmann and Fehr (1996) tried to explain the mechanism of SRTRM of this type on the basis of detailed micromagnetic, rockmagnetic, and mineralogical investigations on dacitic pumice from the 1991 eruption of Mt. Pinatubo. In their work, observation of hemoilmenite crystals using the Bitter technique played an important role. They detected two intergrown hemoilmenite phases in chemically zoned particles in "shell structure" as being responsible for SRTRM: a rim-(or covering)phase consisting of a weak ferromagnetic (WF) (disordered) hemoilmenite phase (low saturation magnetization but magnetically hard like hematite, $X_{\text {ilm }}=$ $0.53 \sim 0.57)$ and a core-phase consisting of a ferrimagnetic (ordered) hemoilmenite phase (high saturation magnetization but magnetically softer, constant $X_{\text {ilm }}=0.58$ ). They proposed a schematic model of the SRTRM in which the magnetic exchange interaction between these two phases is responsible for the acquisition of SRTRM. However, in their model, according to the phase-diagram by Ishikawa (1962), the Curie point of the ferrimagnetic ordered phase of $X_{i l m}=0.58$ is a little higher than or almost the same as those of the disordered WF phase of $X_{i l m}=0.53 \sim 0.57$. Even if we take into account the difference in the $\mathrm{TiO}_{2}$-content between these two phases, we could not find any significant difference in the Curie points of these two phases. Therefore, the ferrimagnetic-ordered phase in their model should be first magnetized in the normal direction without any interaction with the magnetization of the disordered WF phase.

If we suppose Ishikawa's data are a little different from the magnetic properties of natural hemoilmenite concerned here (such a case is possible in nature), and Hoffmann and Fehr's (1996) model is true, then their proposed mechanism should be adaptable for at least the SRTRM in Haruna dacite pumice. This means that at least two intergrown hemoilmenite phases, one being ferrimagnetic and the other WF, should coexist in single crystals of hemoilmenite of Haruna dacite pumice, whatever the structure may be. In order to evaluate Hoffmann and Fehr's model, we examined micromagnetic structure of hemoilmenite crystals in Haruna dacite pumice samples which show SRTRM, as well as the magnetic behaviour of these dacite pumice samples. In this paper, we report on the experimental results from Haruna dacite pumice samples and discuss the mechanism of "Haruna-type" SRTRM.

\section{Samples}

In May-June, 1998, we collected some non-oriented pumice fragment samples (around 10-20 $\mathrm{cm}$ in size) at four sites in the Futatsu-dake dacite pumice flows/falls area (site $\mathrm{H} 1, \mathrm{H} 2, \mathrm{H} 3$, and $\mathrm{K}$ ) which are very close to the historical site where the "Haruna dacite pumice samples" (Nagata et al., 1951; Uyeda, 1958) had been collected. We measured the NRM and TRM of these rock samples and confirmed that all our samples show SRTRM or "partial SRTRM" (as will be mentioned later). This fact indicates that we are definitely re-examining "Haruna dacite pumice samples" of the same origin as those of Nagata et al. (1951) and Uyeda (1958), etc. In this study, like as in Nagata et al. (1951) and Uyeda (1958), etc., we did not distinguish whether the pumice sample is of pumice flow or of pumice fall origin. Detailed geological examination of the difference in the magnetic properties between Futatsu-dake pumices of flows and falls will be reported in another paper in the future.

For this study, we chose two block samples from those collected at each site $\mathrm{H} 1$ and $\mathrm{K}$, respectively, and one block sample from those at each site $\mathrm{H} 2$ and $\mathrm{H} 3$, respectively. That is, we studied six block samples $\left(\mathrm{H} 1, \mathrm{H}^{\prime}{ }^{\prime}, \mathrm{H} 2, \mathrm{H} 3, \mathrm{~K}\right.$, and $\left.\mathrm{K}^{\prime}\right)$. One-inch cores (volume is about $12 \mathrm{~cm}^{3}$ ) were prepared from these six block samples for the measurement of NRM and TRM. Polished sections of rock samples and also extracted hemoilmenite single crystals were prepared for optical and micromagnetic observations and EPMA analysis.

\section{Experiments and Results}

\subsection{AF-demagnetization of NRM and TRM}

Figure 1 shows the intensity change of AF-demagnetization of the NRM of four samples, H1, H1', H2, and H3. A large difference between the behaviours of $\mathrm{H} 1, \mathrm{H} 2, \mathrm{H} 3$, and $\mathrm{H}^{\prime}{ }^{\prime}$ was observed. That is, the NRM of H1, H2, H3 is composed of two components which are anti-parallel with each other and with different hardnesses. In H1, H2, H3, the softer component is weak in intensity and the harder component is dominant, showing a maximal value. On the other hand, in $\mathrm{H1}^{\prime}$, it appears that the NRM is entirely composed of a soft component.

Figure 2 shows the intensity change of the AF-demagnetization of the TRM of the six samples. Four samples (H1, H2, $\mathrm{H} 3, \mathrm{~K}^{\prime}$ ) showed SRTRM at room temperature when cooled from $600^{\circ} \mathrm{C}$ to room temperature in air in a field of $50 \mu \mathrm{T}$. The normal TRM at room temperature of the two samples $\left(\mathrm{H}^{\prime}, \mathrm{K}\right)$ is weak in intensity and reversed easily at an AF-field of around $5 \mathrm{mT}$. The intensity of the component appeared in the opposite direction at an AF-field of around $5 \mathrm{mT}$ is very weak but hard. On the other hand, the SRTRM of H1, $\mathrm{H} 2, \mathrm{H} 3$, and $\mathrm{K}^{\prime}$ is strong and hard against the AF-field compared with the normal TRM of $\mathrm{H}^{\prime}{ }^{\prime}$ and $\mathrm{K}$, showing a bottom at around 10 20 mT. Figures 1 and 2 are well correlated with each other and all these results indicate that the TRM (NRM) of these samples consists of two components, one is normal and soft (completely demagnetized around 10 20 $\mathrm{mT}$ ) and the other is reversed and comparatively hard. In the case of the two samples $\left(\mathrm{H}^{\prime}, \mathrm{K}\right)$, the reversed hard component is so weak that it is masked by the normal soft component, while in the case of the four samples $(\mathrm{H} 1, \mathrm{H} 2, \mathrm{H} 3$, $\mathrm{K}^{\prime}$ ), the reversed hard component is strong enough but partially cancelled by the superimposed weak and soft normal component. Just as our predecessors did, we know that the 


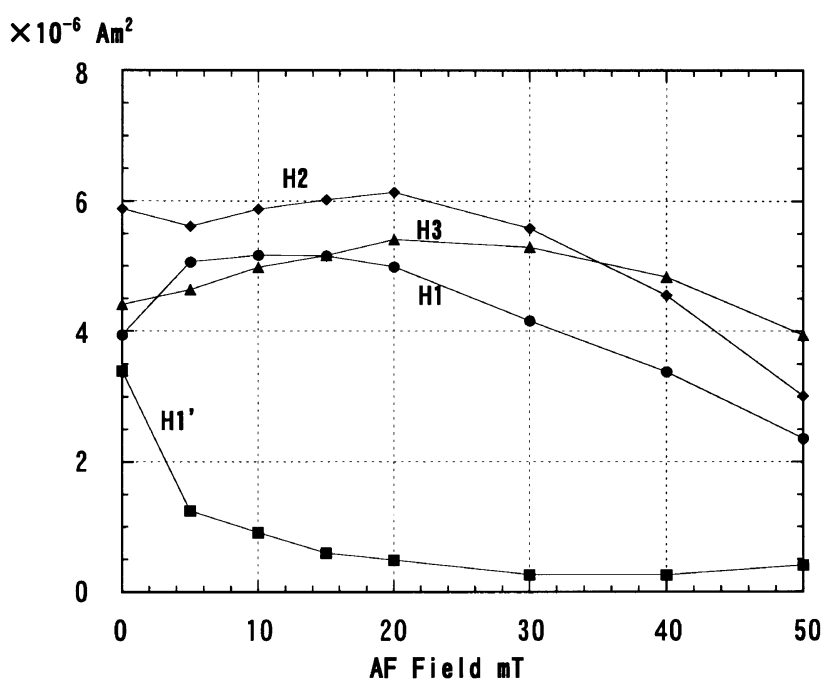

Fig. 1. AF-demagnetization of NRM of Haruna dacite pumice samples of 1 -inch core. Note that the value of the remanent magnetization in the ordinate is shown as the intensity of magnetic moment of the 1 -inch core (volume $\sim 12 \mathrm{~cm}^{3}$ ).

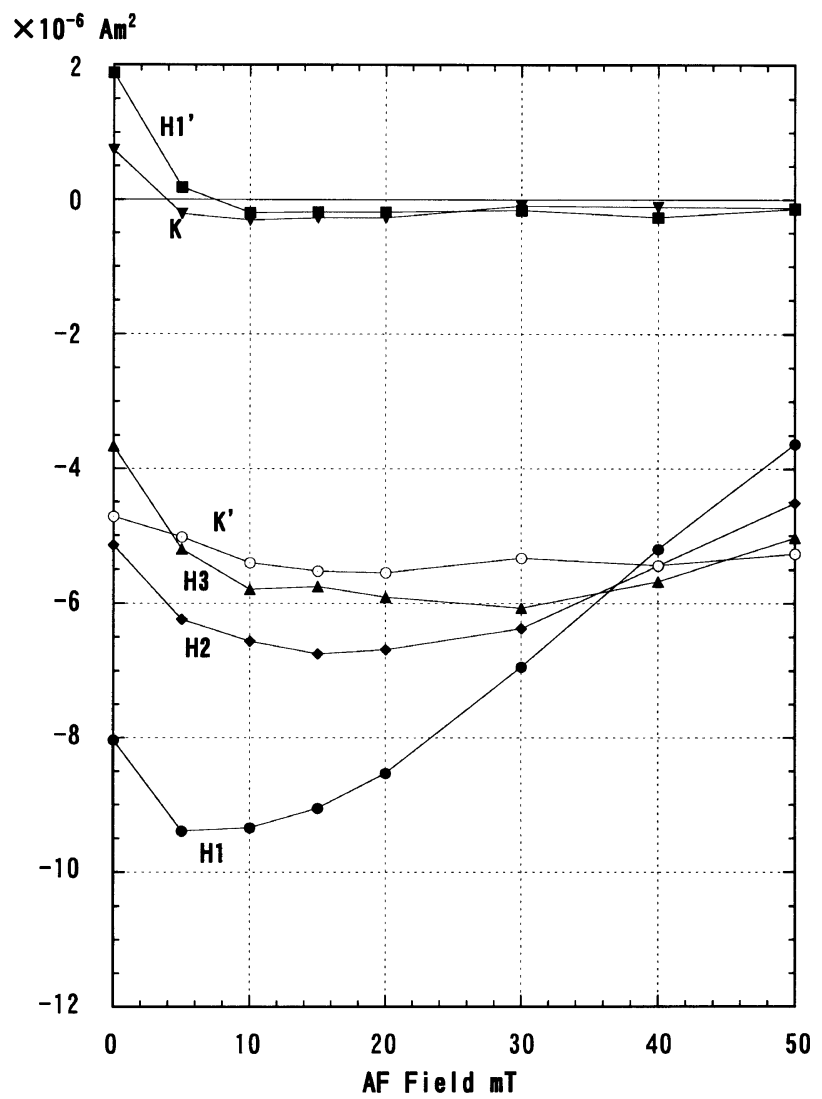

Fig. 2. AF-demagnetization of TRM of Haruna dacite pumice samples. The sign of the TRMs is plus/minus when the TRM is parallel/antiparallel to the applied field.

normal component of TRM (NRM) is carried by titanomagnetite (the Curie point is around $500^{\circ} \mathrm{C}$ ), while the reversed component of TRM (NRM) is carried by hemoilmenite (the Curie point is around $200-300^{\circ} \mathrm{C}$ ). The normal component

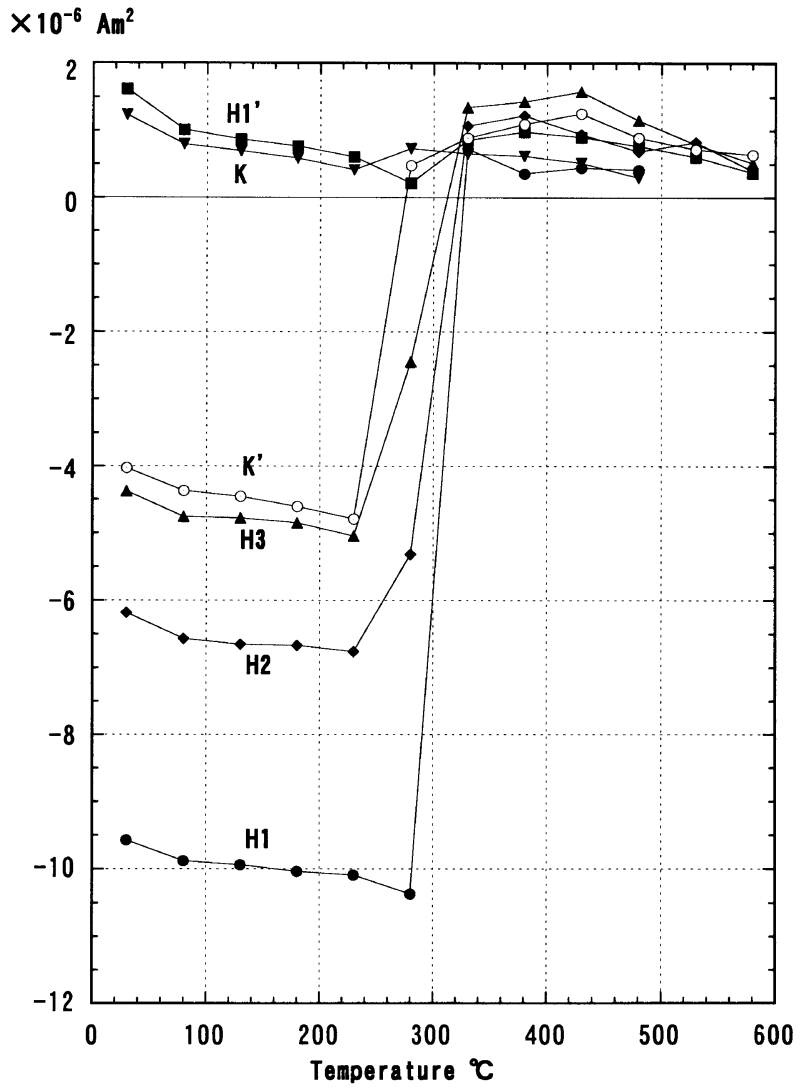

Fig. 3. Thermal-demagnetization of TRM of Haruna dacite pummice samples.

$\times 10^{-6} \mathrm{Am}^{2}$

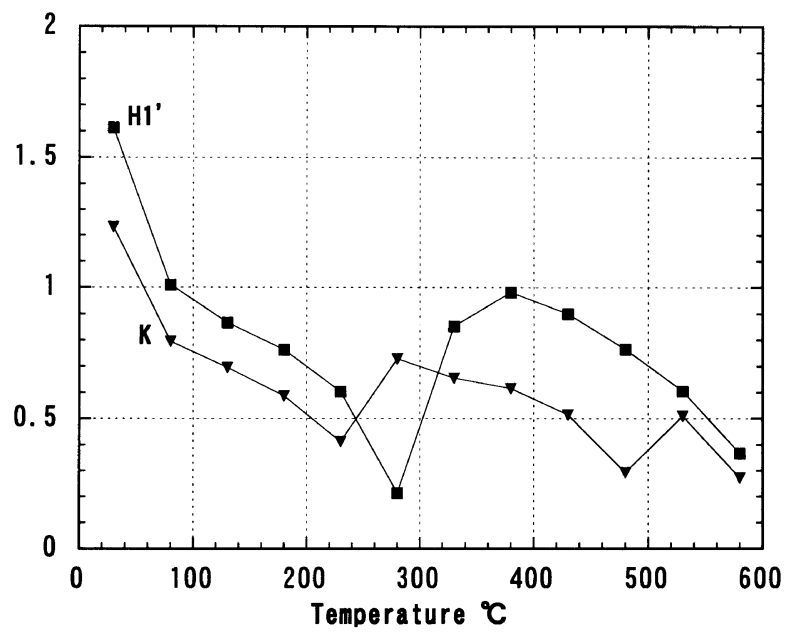

Fig. 4. Enlarged representation of thermal-demagnetization of TRM of two Haruna dacite pumice samples $\left(\mathrm{H} 1^{\prime}, \mathrm{K}\right)$ which showed partial SRTRM.

of TRM (NRM) of titanomagnetite does not have any role to play in the acquisition of the reversed component of TRM.

\subsection{Thermal-demagnetization of TRM}

Figure 3 shows the intensity change during the thermaldemagnetization of the TRM of the six samples. On thermaldemagnetization of TRM in air, the normal TRM at room temperature shown by the two samples $\left(\mathrm{H}^{\prime}{ }^{\prime}, \mathrm{K}\right)$ showed a de- 
Table 1. $\mathrm{TiO}_{2}$-content of hemoilmenite grains in Haruna dacite pumice sample (H2).

\begin{tabular}{cccc}
\hline \multirow{2}{*}{ Grain } & \multicolumn{3}{c}{$\mathrm{TiO}_{2}$-content } \\
\cline { 2 - 4 } & Range $(\mathrm{wt} \%)$ & Mean $(\mathrm{wt} \%)$ & Number of averaged points \\
\hline $\mathrm{H} 2-1$ & $33.0 \sim 31.7$ & 32.3 & 8 \\
$\mathrm{H} 2-2$ & $31.2 \sim 29.4$ & 30.7 & 10 \\
$\mathrm{H} 2-3$ & $30.7 \sim 29.3$ & 30.0 & 5 \\
$\mathrm{H} 2-4$ & $31.2 \sim 29.4$ & 30.3 & 10 \\
$\mathrm{H} 2-5$ & $30.8 \sim 30.2$ & 30.6 & 9 \\
$\mathrm{H} 2-6$ & $31.0 \sim 29.8$ & 30.5 & 5 \\
\hline
\end{tabular}

pression (kink) around $200-300^{\circ} \mathrm{C}$. This situation is shown in Fig. 4 on an enlarged scale. On the other hand, the SRTRM shown by the four samples $\left(\mathrm{H} 1, \mathrm{H} 2, \mathrm{H} 3, \mathrm{~K}^{\prime}\right)$ increased until it reached $250^{\circ} \mathrm{C}$ and then changed sign into the normal direction around $300^{\circ} \mathrm{C}$, showing a kink around $200-300^{\circ} \mathrm{C}$. This normal component increased slightly then finally decreased to disappear around $500-600^{\circ} \mathrm{C}$. These results again indicate that, for all these samples, TRM is composed of two components. One is normal and the other is reversed. The Curie point (or unblocking temperature) of the reversed component is around $200-300^{\circ} \mathrm{C}$ and that of the normal component is around $500^{\circ} \mathrm{C}$. For the former two samples $\left(\mathrm{H}^{\prime}\right.$, $\mathrm{K})$, the intensity of the normal component is larger than that of the reversed component, resulting in the acquisition of apparent normal TRM at room temperature, but containing a hidden weak reversed TRM component. We say these samples showed "partial SRTRM". For the latter four samples $\left(\mathrm{H} 1, \mathrm{H} 2, \mathrm{H} 3, \mathrm{~K}^{\prime}\right)$, the intensity of the reversed component itself is large and is larger than that of the normal component, resulting in the acquisition of SRTRM at room temperature, but containing a hidden weak normal TRM component.

Figures 2 and 3 are well correlated with each other and these results are consistent with the original data of Nagata et al. (1951), Uyeda (1958), and others. We carried out these elemental experiments in order to be sure that we are now dealing with samples of the same origin and behaviour as those of the historical experiments. These experiments are merely a trace of the former studies. It is new knowledge acquired in this section that even a "Haruna pumice sample" which does not show SRTRM at room temperature (such samples were discarded in the early time of the discovery of SRTRM), has the potential to show SRTRM as "partial SRTRM".

\subsection{Electron microprobe analysis}

Electron microprobe analysis of opaque minerals in Haruna dacite pumice has been carried out by Oshima (1971, 1975, 1980, 1982). Polished sections were prepared from every rock sample (non-heated). As was expected, (almost) all opaque minerals which appeared on the surface of the polished section are titanomagnetite crystals. Only in the sections of the sample $\mathrm{H} 2$, could we recognize one to a few hemoilmenite grains (crystals) per section. We examined the chemical compositions $\left(\mathrm{TiO}_{2}, \mathrm{MnO}, \mathrm{FeO}, \mathrm{Al}_{2} \mathrm{O}_{3}, \mathrm{MgO}\right)$ of these hemoilmenite crystals. The compositions were considerably homogeneous in each grain within our measurement error and any systematic change in the compositions in a

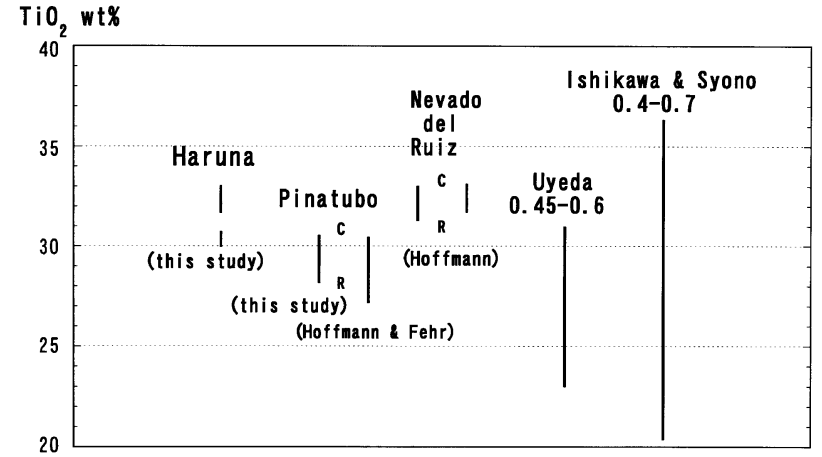

Fig. 5. $\mathrm{TiO}_{2}$-content of hemoilmenite which shows SRTRM. The numbers under the names indicate the range of $X_{i l m}$ mentioned in their papers to show SRTRM. The upper bar in Haruna indicates the range of the $\mathrm{TiO}_{2}$-content observed within the grain $\mathrm{H} 2-1$ in this study. The lower bar indicates the range of the $\mathrm{TiO}_{2}$-content in the five grains, $\mathrm{H} 2-2 \sim \mathrm{H} 2-6$ in Table 1. C: core, R: rim. Data of Nevado del Ruiz (Hoffmann, private communication, 1999) and Pinatubo (one is from Hoffmann and Fehr (1996) and the other is from our study) indicate the distribution of the $\mathrm{TiO}_{2}$-content of core to rim in each single crystal.

single grain such as "zoning" was not detected. Our result is very close to those by Oshima (1975). We took the value of $\mathrm{TiO}_{2} \mathrm{wt} \%$ as an indication of the chemical compositions of hemoilmenite in this study and averaged the values in a single grain. These values from six grains are listed in Table 1. As seen in the table, the $\mathrm{TiO}_{2}$-content for five grains is around $30 \mathrm{wt} \%$, while for only one, it is significantly high by about $2 \mathrm{wt} \%$. This implies that there could be a grain-to-grain variation of $\mathrm{TiO}_{2}$-content of $2 \mathrm{wt} \%$ or so in hemoilmenite crystals even in a single fragment sample. This result is shown in Fig. 5 together with those so far reported for the other pumices which showed SRTRM for comparison. In the cases of Mt. Pinatubo and Nevado del Ruiz, the range of the value shows the difference between the rim and the core in a single grain, while in our result of the Haruna samples, the upper bar indicates the range in the grain $\mathrm{H} 2-1$, and the lower bar the grain-to-grain variation in the other five grains. All these values lie within the compositional range where hemoilmenite behaves as an intrinsic order-disorder transformation $\left(X_{\text {ilm }}=0.45 \sim 0.6\right.$ in Uyeda (1957); $X_{i l m}=0.4 \sim 0.7$ in Ishikawa and Syono (1962)). 

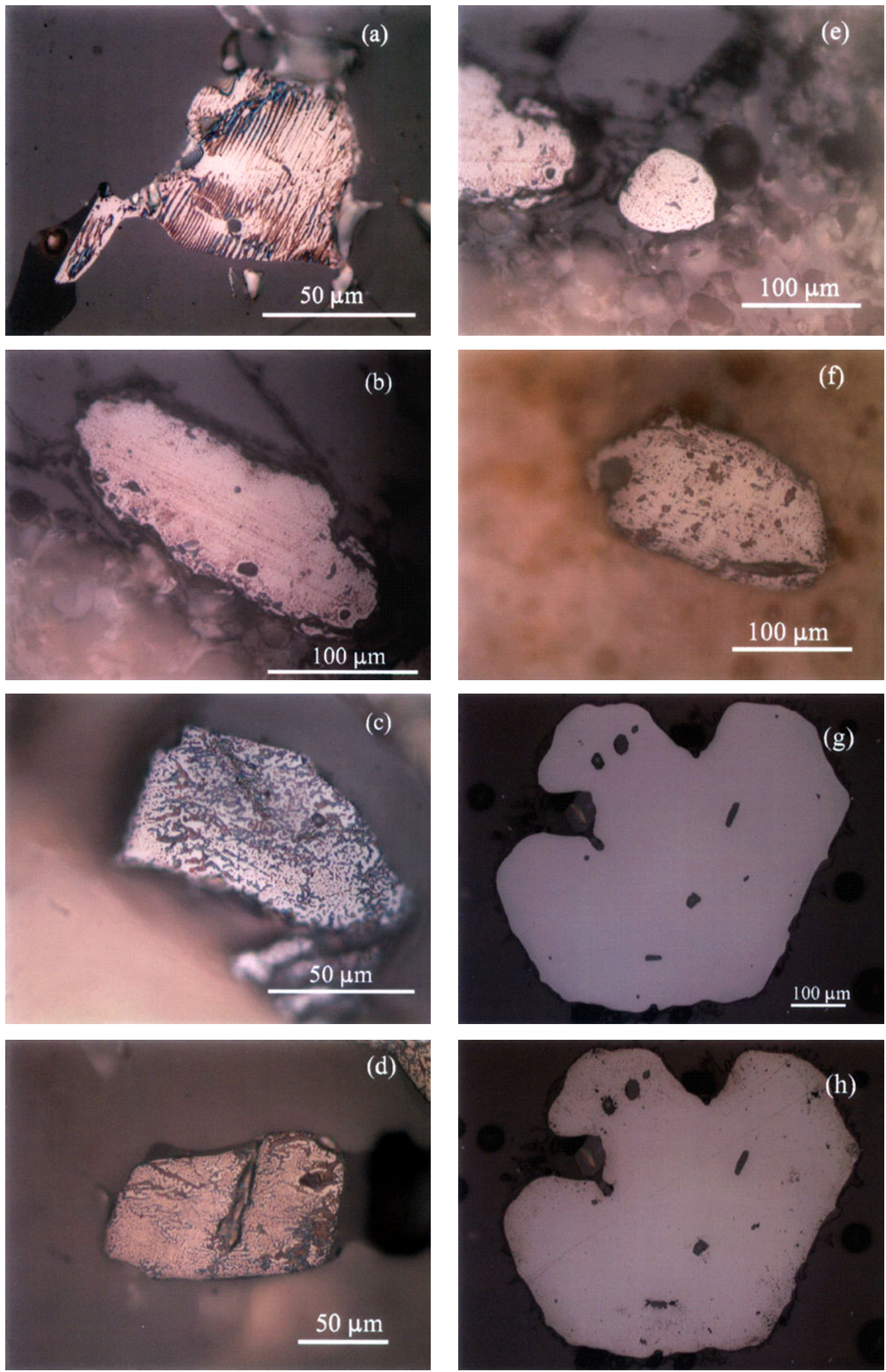

Fig. 6. The Bitter pattern of hemoilmenite crystals in the Haruna dacite pumice sample. (a) grain H2-1, (b) grain H2-5, (c) grain H2-7, (d) grain H2-4, (e) grain H2-6, (f) grain H2-3, (g) Polished surface of the (0001)-plane of a hexagonal plate-shaped single crystal of hemoilmenite without ferrofluid, (h) the Bitter pattern of this surface. 

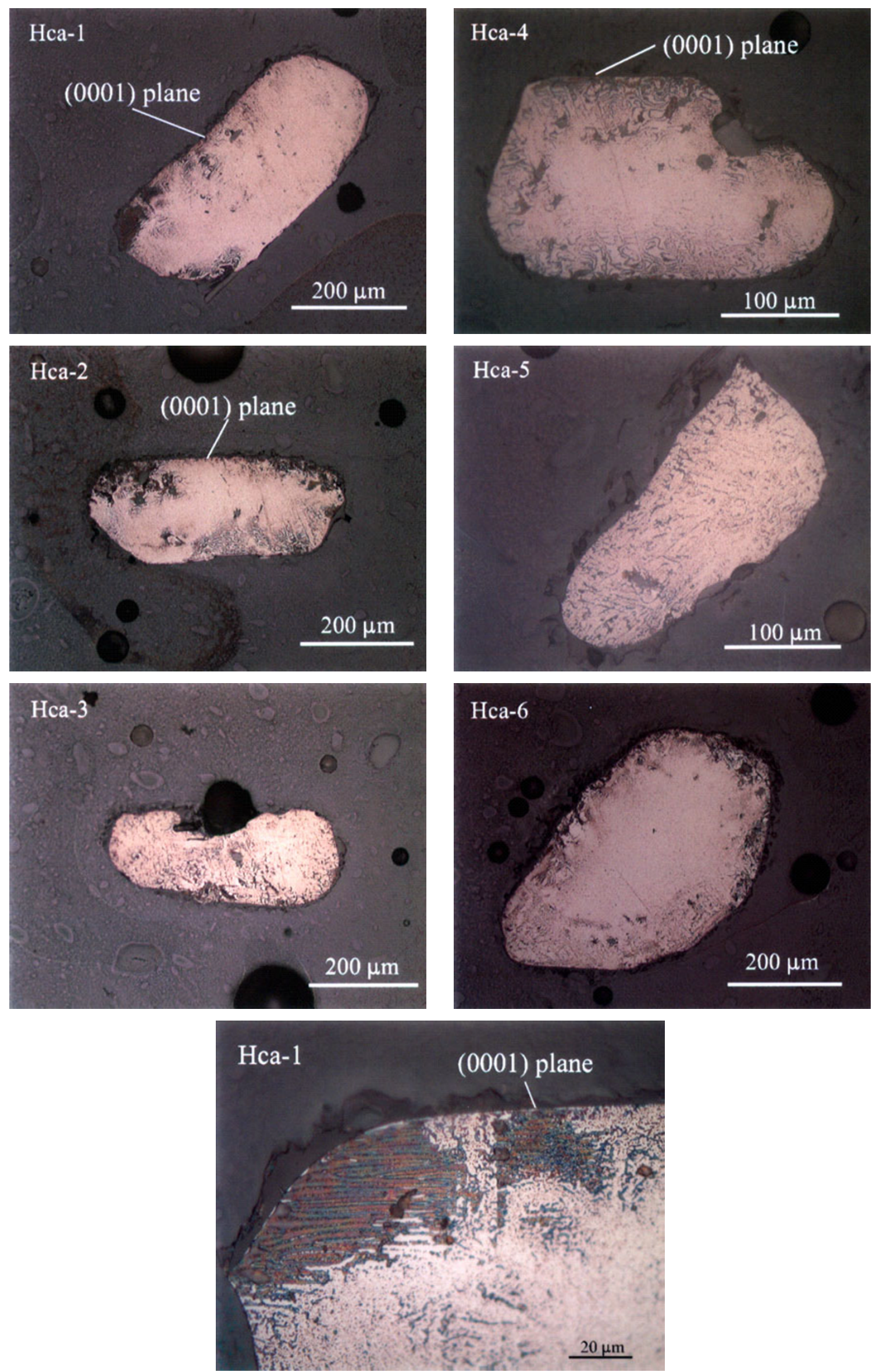

Fig. 7. The Bitter pattern of six oriented single crystals of hemoilmenite in the plane parallel to the c-axis. Three samples (Hca-3, Hca-5, Hca-6) are slightly tilted, while the other three samples (Hca-1, Hca-2, Hca-4) are correctly oriented. The lowest one is a partly enlarged representation of the Bitter pattern of sample Hca-1. 


\subsection{Micromagnetic observation by means of the Bitter technique}

(1) Hemoilmenite single crystals (discrete or inclusion) in the rock sections.

Figure 6 shows some examples of the Bitter pattern of hemoilmenite crystals which happened to appear with arbitrary crystal orientation on the polished surfaces of the sections. The grain H2-1 (Fig. 6(a)) showed a homogeneous and typical bright uniaxial ferrimagnetic parallel wall structure without WF rim or core. In the grain H2-5 (Fig. 6(b)), faint $180^{\circ}$ walls were observed parallel to the elongation in the viewing surface of the grain. In the grains H2-7 (Fig. 6(c)), H2-4 (Fig. 6(d)) and H2-6 (Fig. 6(e)), a sort of "cauliflower structure" was observed. In the grain H2-2 (not shown in the figure), no clear walls were observed, while the grain H2-3 (Fig. 6(f)) showed small patches of the ferrimagnetic parallel wall region at the rim. In all these cases, neither zoning-like shell structures of two phases nor WF structures (Bina et al., 1999) were observed.

(2) Oriented single crystals (observation in the c-plane).

From the magnetic fraction of samples $\mathrm{H} 1$ and $\mathrm{H} 3$, we selected some hemoilmenite single crystals of hexagonal plate shape. We mounted two plates of about $0.5 \mathrm{~mm}$ in diameter and $0.2 \mathrm{~mm}$ in thickness and observed the polished surfaces (the c-plane) normal to the c-axis at several stages of the depth. At any stage, neither wall pattern, typical for the ferrimagnetism, nor WF structure were observed. Instead, the ferrofluid adhered mainly to the outer part with an irregular stain-like feature. The inner part is clearer (free from the ferrofluid) than the outer part. The stained outer part changes gradually to the inner clearer part, i.e., no boundary, needed to make a shell structure of two parts, was observed. Figures $6(\mathrm{~g})$ and $(\mathrm{h})$ show an example of this view. As shown, sometimes ferrofluid is attached to both ends of a long silicate inclusion (or non-magnetic defect), indicating that the spin axis (at least here) lies in the c-plane and is along the long edge of the non-magnetic defect. Although these samples show ferrimagnetism as a whole, no wall structure was observed in the c-plane. This fact which includes an implication on the spin-structure of hemoilmenite is discussed later.

(3) Oriented single crystals (observation of the plane parallel to the c-axis).

We mounted six single crystals (Hca-1, Hca-2, ..., Hca6 ) to observe the plane parallel to the c-axis. Three (Hca3 , Hca-5, Hca-6) of them tilted slightly and three (Hca-1, Hca-2, Hca-4) just settled in the ordered direction. Figure 7 shows the Bitter pattern of a section of these crystals. In the three tilted crystals, the contour line-like WF structure (Bina et al., 1999) is mixed with the irregular stain-like or streak-like pattern. On the other hand, in the three correctlyoriented crystals, the typical contour line-like WF structure was spread. In one of them (Hca-1), a small region showing ferrimagnetic $180^{\circ}$ walls parallel to the c-plane and a socalled cauliflower structure as well as a WF structure were observed. The lowest part of this figure shows this part of Hca-1 on an enlarged scale. This fact again proves that the spin-axis lies in the c-plane and rotated within this plane to produce a $180^{\circ}$ Bloch wall and a cauliflower structure in the observed plane. We should mention again that we could not find any shell structure of two phases, even a clear boundary of two phases in all these crystals.

\section{Discussion}

According to Hoffmann and Fehr (1996) and Bina et al. (1999), hemoilmenite crystals of dacite pumice of the 1991 eruption of Mt. Pinatubo, which are responsible for SRTRM, have a shell structure of two phases with different compositions, one is ordered ferrimagnetic and the other is disordered weak ferromagnetic (associated with anti-ferromagnetism). In order to check their results, we have studied our Pinatubo samples with polished sections using microprobe analysis and the Bitter technique. Our results are consistent with those by Hoffmann and Fehr (1996) and Bina et al. (1999) that hemoilmenite has a shell structure of two phases with different compositions and magnetism. Figure 8 shows two examples of hemoilmenite crystals in our Pinatubo samples in which the shell structure is commonly observed. A similar shell structure was also found in hemoilmenite in other SRTRM samples (e.g., samples from Nevado del Ruiz (Hoffmann, private communication, 1999); granulite samples from Rio Grande Rift (given by Dr. P. Wasilewski (Ozima, to be published)).

However, Haruna samples without any distinct shell structure (with two phases with different magnetism and compositions in a single crystal of hemoilmenite) showed SRTRM. As the Haruna sample is "the origin of SRTRM", naturally, the model of SRTRM should be common throughout both Pinatubo and Haruna samples. In this respect, we would emphasize that the common factor in these two cases is the coexistence of the two phases (ferrimagnetic and WF) in single crystals of hemoilmenite, irrespective of structure. That is, the geometry of the structure of two phases itself (shell structure or not) in a single hemoilmenite crystal is not essential for the acquisition of SRTRM of this type. Therefore, we presume that the essential point of Hoffmann and Fehr's model and Bina et al.'s model (abbr. HF-model) is not the shell structure, but that the two phases (of different compositions and magnetism) coexist in a single crystal of hemoilmenite with or without a structure. In this case, of course, the actual Curie point of the disordered WF phase should be higher than that of the ordered phase. To prove this experimentally would be a most important key. Moreover, according to Uyeda (1957), the intensity of the SRTRM of hemoilmenite itself is sensitive to the heat treatment of the sample. According to Ishikawa and Syono (1962), the magnetic properties of hemoilmenite change with annealing at $700^{\circ} \mathrm{C}$. But, in the HF-model, the boundary between the two phases with different compositions in a hemoilmenite crystal may be fixed and could not be moved by heat treatment (e.g. at around $700^{\circ} \mathrm{C}$ ) or even in the process of the production of TRM, as the diffusion by which the bulk compositions are changed would not take place at such temperatures. Therefore, the sensitivity of the intensity of (SR)TRM to the heat treatment would not be interpreted with the shell structure model (HF-model).

In Ishikawa and Syono's model, we do not need either such a visible structure or such a distribution of $\mathrm{TiO}_{2}$-content in a hemoilmenite crystal, therefore, our experimental results support Ishikawa and Syono's model. However, taking all 

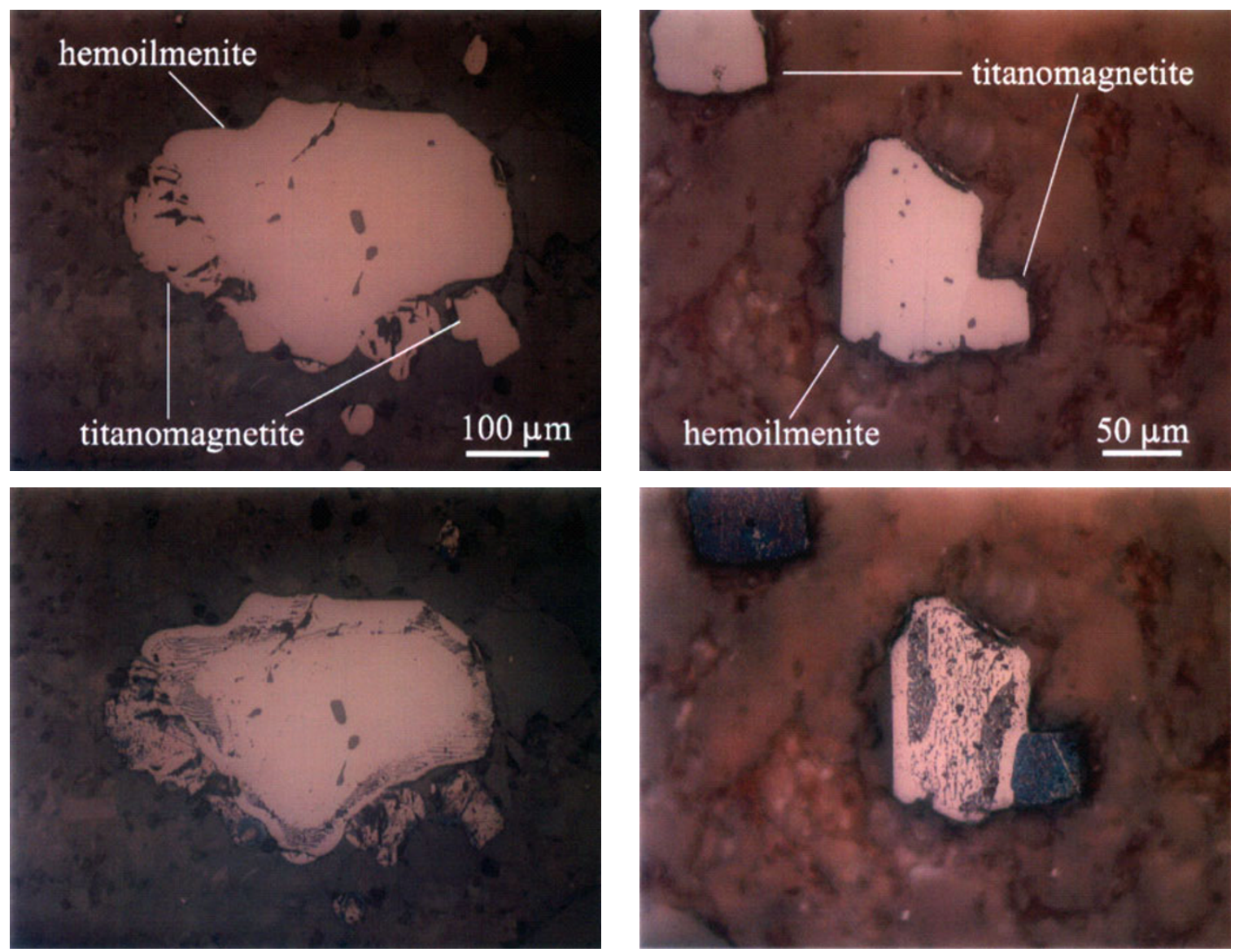

(a)

(b)

Fig. 8. Examples of the polished surface without ferrofluid (upper) and the Bitter pattern (lower) of hemoilmenite crystals in Pinatubo dacite pumice. A typical shell structure was observed. (a) WF rim and core, between them ferrimagnetic phase exists. (b) Twinned ferrimagnetic hemoilmenite crystals core with the WF rim.

our results into account, and comparing the HF-model with Ishikawa and Syono's model, we became aware of the fact that there are no essential differences in these two models. The HF-model is on a microscopic scale where the phase which lets the magnetization of ordered ferrimagnetic phase reverse is the intergrown $\mathrm{Fe}$-rich disordered WF phase region, while Ishikawa and Syono's model is of the lattice scale where the Fe-rich disordered (intermediate) phase (the "X-phase") reverses the magnetization of the ordered ferrimagnetic phase. In both cases, the disordered/intermediate phase should have/has a higher Curie point than that of the ordered phase. We may conclude that both models are basically acceptable.

As for the spin-axis of the hematite-ilmenite solid solution series, Brown et al. (1993) mentioned that below the Néel temperature, compositions $X_{i l m} \leq 0.5$ are antiferromagnetic with magnetic moments aligned as in hematite. Samples with compositions in the range $0.50<X_{\text {ilm }}<0.75$ are ferrimagnetic at room temperature, with the net magnetic moments aligned parallel to the c-plane ((0001) plane). Hoffmann and Fehr's (1996) and Bina et al.'s (1999) descriptions on the spin-alignment of this series contradicts the above-mentioned Brown et al.'s (1993) result. In our case of Haruna samples, the results obtained from the Bitter pattern of hemoilmenite crystals support the arguments by Brown et al. (1993) and Goguitchaichvili and Prévot (2000). However, it must be mentioned that whichever the spin-axis of hemoilmenite would be aligned, the direction of the alignment would not contribute to the mechanisms in those two models.

If the hemoilmenite is a ferrimagnetic crystal in which the spin axis lies in the c-plane, and since this crystal has a hexagonal symmetry, we may be able to observe $120^{\circ}$ and $60^{\circ}$ walls as well as $180^{\circ}$ wall in the c-plane, but in our result obtained in Subsection 3.4(2), in the c-plane of the single crystal of hemoilmenite, no distinct wall structure was observed with the Bitter technique. Why? The one plausible hypothesis is as follows. In hemoilmenite crystals of multidomain size which is of concern here, the moments (spinaxis) aligned in the c-plane could not construct Bloch walls within the c-plane with the rotation of the spin, because the crystalline anisotropy energy for the spin to turn into the caxis is too large. In such a case, other types of wall (e.g. Néel wall) instead of the Bloch wall would be formed in the c-plane. Actually, in our study, Bloch wall with spin-axis rotation within the c-plane was observed only in the plane parallel to the c-axis (Fig. 7). This supports the possibility of the existence of a Néel wall when observed in the c-plane. 
Other techniques for observation of walls will be needed to make sure that this hypothesis is correct.

\section{Conclusion}

Unlike the results on self-reversing Pinatubo dacite pumice samples by Hoffmann and Fehr, we could not find any such "shell structure" in the Bitter pattern in the polished surfaces of hemoilmenite crystals in self-reversing Haruna dacite pumice samples. Instead, we found that both ordered ferrimagnetic and disordered WF phases in these hemoilmenite crystals coexist in single crystals without distinct structures. Accordingly, the essentials of SRTRM could not be related to the structure but the coexistence of two intergrown hemoilmenite phases with different compositions and magnetism in single crystals, one being the ordered ferrimagnetic phase and the other a disordered WF phase, irrespective of the structure. To accept this model, we need to prove that the Curie point of the disordered WF phase is higher than that of the ordered ferrimagnetic phase.

Our result from the Bitter pattern of the oriented hemoilmenite crystals supports the argument by Brown et al. (1993) that the spin-axis of hemoilmenite crystals is confined in the basal plane ((0001) plane).

Acknowledgments. We are grateful to Dr. V. Hoffmann of the University of Tübingen for his helpful comments and advice on the Bitter technique. From the viewpoint of geology, Dr. O. Oshima of the University of Tokyo made some important comments, for which we are very grateful. Comments and suggestions by Laurie Brown and an anonymous reviewer helped to improve the manuscript.

\section{References}

Bina, M., J. C. Tanguy, V. Hoffmann, M. Prévot, E. L. Listanco, R. Keller, K. Th. Fehr, A. T. Goguitchaïchvili, and R. S. Punongbayan, A detailed magnetic and mineralogical study of self-reversed dacitic pumices from the 1991 Pinatubo eruption (Philippines), Geophys. J. Int., 138, 159-178, 1999.

Brown, N. E., A. Navrotsky, G. L. Nord, Jr., and S. K. Banerjee, Hematiteilmenite $\left(\mathrm{Fe}_{2} \mathrm{O}_{3}-\mathrm{FeTiO}_{3}\right)$ solid solutions: Determinations of Fe-Ti order from magnetic properties, Am. Mineral., 78, 941-951, 1993.

Goguitchaichvili, A. and M. Prévot, Magnetism of oriented single crystals of hemoilmenite with self-reversed thermoremanent magnetization, $J$ Geophys. Res., 105(B2), 2761-2780, 2000.

Haag, M., F. Heller, M. Lutz, and E. Reusser, Domain observations of the magnetic phases in volcanics with self-reversed magnetization, Geophys. Res. Lett., 20(8), 675-678, 1993.
Heller, F., J. C. Carracedo, and V. Soler, Reversed magnetization in pyroclastics from the 1985 eruption of Nevado del Ruiz, Colombia, Nature, 324, 241-242, 1986.

Hoffman, K. A., Self-reversal of thermoremanent magnetization in the ilmenite-hematite system: order-disorder, symmetry and spin alignment, J. Geophys. Res., 97(B7), 10883-10895, 1992.

Hoffmann, V. and K. Th. Fehr, Micromagnetic, rockmagnetic and mineralogical studies on dacitic pumice from the Pinatubo eruption (1991, Philippines) showing self-reversed TRM, Geophys. Res. Lett., 23, 28352838, 1996.

Ishikawa, Y., Magnetic properties of ilmenite-hematite system at low temperature, J. Phys. Soc. Japan, 17, 1835-1844, 1962.

Ishikawa, Y. and Y. Syono, Reverse thermo-remanent magnetism in the $\mathrm{FeTiO}_{3}-\mathrm{Fe}_{2} \mathrm{O}_{3}$ system, J. Phys. Soc. Japan, 17(B-1), 714-718, 1962.

Ishikawa, Y. and Y. Syono, Order-disorder transformation and reverse thermoremanent magnetism in the $\mathrm{FeTiO}_{3}-\mathrm{Fe}_{2} \mathrm{O}_{3}$ system, Phys. Chem. Solids, 24, 517-528, 1963.

Kennedy, L. P., Self-reversed thermoremanent magnetization in a late Brunhes dacite pumice, J. Geomag. Geoelectr., 33, 429-448, 1981.

Lawson, C. A., G. L. Nord, Jr., and D. E. Champion, Fe-Ti oxide mineralogy and the origin of normal and reverse remanent magnetization in dacitic pumice blocks from Mt. Shasta, California, Phys. Eearth Planet. Inter. 46, 270-288, 1987.

Nagata, T., S. Akimoto, and S. Uyeda, Reverse thermo-remanent magnetism, Proc. Jap. Acad., 27, 643-645, 1951.

Nord, G. L., Jr. and C. A. Lawson, Order-disorder transition-induced twin domains and magnetic properties in ilmenite-hematite, Am. Mineral., 74, 160-176, 1989.

Oshima, O., Compositional variation of magnetite during the eruption and its bearing on the stage of crystallization of magma of Futatsu-dake, Haruna volcano, Mineral. J., 6, 249-263, 1971.

Oshima, O., Mineralogical aspects of volcanic eruption, Bull. Volc. Soc. Japan, ser. 2, 20, 275-298, 1975 (in Japanese).

Oshima, O., Oxidation exsolution of titanomagnetite in a dacite from Haruna volcano, Sci. Pap. Coll. Gen. Educ. Univ. Tokyo, 30, 79-87, 1980.

Oshima, O., Reduction decomposition of hemoilmenite in a cooling magma and its relation to the changes of magnetization of rocks, Rock Magnetism and Paleogeophysics, 9, 102-105, 1982.

Ozima, M., M. Funaki, N. Hamada, S. Aramaki, and T. Fujii, Self-reversal of thermo-remanent magnetization in pyroclastics from the 1991 eruption of Mt. Pinatubo, Philippines, J. Geomag. Geoelectr., 44, 979-984, 1992.

Sawada, Y., M. Fukue, and M. Hyodo, Paleomagnetic study of the Sambe Volcano: age of dacite domes, temperature of pyroclastic flow, and self-reversed magnetic mineral, Abstracts 1999 Japan Earth and Planetary Science Joint Meeting, Vc-006, Tokyo, Japan, June 8-11, 1999 (in Japanese).

Uyeda, S., Thermo-remanent magnetism and coercive force of the ilmenitehematite series, J. Geomag. Geoelectr., 9, 61-78, 1957.

Uyeda, S., Thermo-remanent magnetism as a medium of paleomagnetism, with special reference to reverse thermo-remanent magnetism, Jap. J. Geophys., 2, 1-123, 1958.

M. Ozima (e-mail: ozima@nipr.ac.jp) and M. Funaki 